\title{
Social determinants of equity in access to healthcare for tuberculosis patients in Republic of Macedonia - results from a case-control study
}

\author{
Dance Gudeva Nikovska ${ }^{1, *}$, Fimka Tozija ${ }^{2}$
}

\begin{abstract}
Background: Health is a complex phenomenon and equity as a basic human right an integral part of constitutions in almost all countries in the world. In Republic of Macedonia (RM), Tuberculosis (TB) is clustered regionally and in certain ethnic groups. The main objective of this study was to analyze Social Determinants of Health $(\mathrm{SDH})$ and equity in access to healthcare services for TB patients in RM, aimed at complex analysis of factors that cause inequities.

Methods: Case-control study was conducted in the period March-December, 2013; "cases" are households of TB patients registered in the period July, 2012-June, 2013 and controls are households with no TB patients in their immediate vicinity. World Health Organization (WHO) World Health Survey questionnaire was used to collect data.

Results: Analysis of SDH of TB patients shows that patients are mostly males, of lower socio-economic status, are less educated, unemployed and TB is clustered in certain ethnic groups. Analysis of access has identified these determinants as important barriers in access to health services.

Conclusion: The study has documented the basic SDH of TB patients in RM, as well as barriers in access to healthcare, providing useful baseline information to facilitate determination where to concentrate future efforts. Keywords: Equity, Social Determinants of Health (SDH), Tuberculosis (TB) Patients, Macedonia

Copyright: ( 2014 by Kerman University of Medical Sciences

Citation: Gudeva Nikovska D, Tozija F. Social determinants of equity in access to healthcare for tuberculosis patients in Republic of Macedonia - results from a case-control study. Int J Health Policy Manag 2014; 3: 199-205. doi: $10.15171 /$ ijhpm.2014.89
\end{abstract}

Article History:

Received: 29 June 2014

Accepted: 21 September 2014

ePublished: 25 September 2014

\section{Key Messages}

Implications for policy makers

- The gap in health status among poor and wealthier populations in Republic of Macedonia (RM) has never been systematically studied, thus leading to policies and programs that are targeting the entire population, rather than targeting vulnerable groups.

- Achieving improved health equity through addressing the Social Determinants of Health (SDH) is a value-based and often political process involving changes to policies at the institutional, local and national level. Therefore national authorities should focus on designing programs to reduce barriers to access for certain population groups in order to reduce their differential vulnerability, including making services available by removing or reducing fees.

- Healthcare services for Tuberculosis (TB) patients should be provided in a systematic way that will minimise direct and indirect costs, complementary to other social protection interventions, such as family-focused social work support and essential social transfers - in cash and in kind.

- $\quad$ Monitoring of SDH should be integrated into the routine recording and reporting system.

Implications for public

Understanding the main Social Determinants of Health (SDH) that impair access to healthcare is integral to reducing its impact on health; their recognition is not important only for Tuberculosis (TB), but also for achievement of broader public health goals. In an ideal world, individuals should be free to seek and receive appropriate and high quality treatment when diagnosed with TB that will allow for not only treatment of the diseased person, but also control the spread of disease through implementation of appropriate public health measures. People living with TB should experience full compassion, assistance and support from their environment. Such an example would contribute to raising awareness in the general population and a willingness to use preventive measures for treatment and care at the individual level, leading to further containment of TB disease in Republic of Macedonia (RM). 


\section{Introduction}

Inequities in health status and access to healthcare are global problems, equally affecting rich and poor countries (1) and numerous attempts to quantify economic impact of health inequities have shown significant opportunities for savings if these inequities are reduced (2), such as calculations that lost lives due to health inequities account for 700,000 deaths annually and 33 million diseased across European Union (EU) $(3,4)$.

The definition of health as a state of "complete physical, mental and social well-being and not merely the absence of disease or infirmity" (5), although when created considered as revolutionary and no adaptation made to date, is intensively becoming subject to criticism as limited (6), with numerous attempts for its re-definition and need to add other societal and environmental factors. There are increasing criticisms that this definition is even counterproductive (7) because of the aging population, emergence of new diseases $(8,9)$ and persistence of many so-called "old" diseases, such as malaria, Tuberculosis (TB), and sexually transmitted diseases.

Social Determinants of Health $(\mathrm{SDH})$ are defined as "the conditions in which people are born, grow, live, work and age, including the health system" (10), shaped by the distribution of money, power and resources at global, national and local levels (11), and are increasingly recognized as main factors to be tackled in order to control diseases (12). This increasing evidence has resulted in formulation of the new World Health Organization (WHO) post-2015 TB strategy (13), where one of the four pillars focuses on social protection, poverty alleviation, and actions on other determinants of TB. It was also emphasized in 2014 World TB Day main message as "urgent to ensure that everyone suffering from $T B$ has access to adequate TB care, including diagnosis, treatment and cure" (14). Following its independence in 1991, Republic of Macedonia (RM) has faced numerous challenges in all sectors of society, in the transition towards development of parliamentary democracy and preserving social values based on democracy, citizen's participation, and right to private property (15). Equity as a basic human right is stipulated in the Constitution (16), defining right to health for each citizen in Article 39. The country today is struggling with diverse healthcare challenges, with the healthcare jigsaw cutting across quality of care, decaying infrastructure, affordability, patient safety, rural-urban divide, as well as the dual burden of both communicable and lifestyle diseases (17).

Although TB has been constantly decreasing in the country over the past decade, with an incidence of 17.2/100.000 in 2012 that classifies RM as a low incidence country (18), TB is clustered in certain ethnic groups, with highest rates (as documented in the national electronic recording and reporting system) in the North-West part of the country, in male population with ratios of 1.5:1-1.3:1 in the period 200713. The most affected is age group $25-54$ years. Data on SDH is not routinely collected, nor monitored; therefore there is an implicit need to study SDH in national context.

The main objective of the survey was to analyze SDH and access to healthcare services for TB patients in RM, aimed at complex analysis of the reasons for disease clustering, main social determinants of TB patients and factors that can cause or are causing inequities in access to healthcare, in order to provide evidence on barriers and provide recommendations for targeted interventions. The survey tests the hypothesis that TB patients do not have different social determinants than the general population and that the health system in Macedonia is equitable and provides equal access to healthcare for TB patients.

\section{Setting}

The reestablishment of the healthcare system in 1991 was based on consolidation of the large health infrastructure inherited from the previous system, following the principles of solidarity, mutuality and citizens' participation defined in the constitution. It is a health insurance-based system in which payroll-dependent contributions are collected and the funds are managed by the Health Insurance Fund (HIF). Together with the Ministry of Health, the HIF steers the sector and agrees contracts with service providers. Health insurance coverage is universal and the benefits package comprehensive. National Tuberculosis Program is one of the oldest disease control programs in the country, dating back to 1929; with several revisions to date, based on WHO recommendations. $\mathrm{TB}$ is priority of the health authorities in the country, along with HIV/AIDS, mother and child care, and immunization.

\section{Methods}

The study was conducted in 8 statistical regions in RM (population of 2,065,769 inhabitants, 2013) (19) in the period March-December, 2013. Informed consent was an integral part of the questionnaire and was obtained from each survey participant.

By means of case-control study, households with registered TB cases during the period July, 2012-June, 2013 were recruited as "cases" and one control was randomly chosen in households in the cases' immediate vicinity and who agreed to participate in the study, to provide for comparison with the general population.

Data was collected with selected modules from the World Health Survey questionnaire (20), modified to provide data for the survey objectives, in accordance with guidelines for developing countries (21). The instrument was designed to collect a broad range of data associated with everyday functioning of households, such as demographic data, economic activity, consumption of goods and services, living conditions, lifestyle, health status, and access to health services of household members.

Social determinants were assessed by collected data on gender, place of residence (urban/rural), educational and employment status, ethnicity, and the region where the patient lived. Access to healthcare for TB patients and controls was assessed with the question: "Did you or a member of your family need healthcare in the past 30 days, Did you or a member of your family need healthcare in the past year and Last time you needed healthcare, did you receive it?" (Yes-No option), followed by 2 questions on the institution they went to seek healthcare and reasons for not receiving the needed service.

Face-to-face interviews were performed by 20 trained Directly 
Observed Treatment (DOT) nurses who visited TB patients 3 times/week; all data on variables were based on self-reported information.

The instrument was pre-tested on $10 \%$ of the sample, with appropriate corrections following feedback from the pre-test, mainly additional explanations for better understanding of questions. The instrument was also translated into Albanian to allow for interviewing ethnic minorities in RM into their mother tongue.

Data were analyzed with IBM SPSS 19.0 (IBM Corporation, Somers, NY, USA), using descriptive statistics to calculate frequencies and mean values. Percentages were used to express values and Chi-Square test to analyze differences between cases and controls for categorical variables. Multiple logistic regression was used to assess the relationship between access to healthcare as a single categorical response and age, gender, place of residence, region, educational, and employment status as categorical explanatory variables $(22,23)$.

\section{Results}

The total study population included 605 respondents. Three hundred and fifteen respondents were TB cases, equivalent to $96.00 \%$ of registered TB patients in the period July, 2012-June, 2013 , as the main inclusion criterion for "cases". Two hundred and ninety respondents who live in households $(\mathrm{HH})$ in the TB patient's immediate vicinity were recruited as "controls", to provide for comparison with the general population that is disease-free. Characteristics of study population are presented in Table 1.

Respondents represented all 8 regions, as per statistical division of the country. Most of them were interviewed in the North-West region, 47.58\% in Skopje region, 14.96\% in Polog, South-West 8.45\%, South-East and North-East with 7.42\% and $7.24 \%$, respectively, Pelagonija 5.93\%, East 5.28\%, and the lowest number in Vardar region (3.14\%), which corresponds to the distribution of TB patients registered in the period July, 2012-June, 2013. The percentage of controls in the same regions was identical, or negligibly lower or higher compared to cases.

The distribution of respondents by place of residence was quite proportional with $50.92 \%$ living in urban and $49.08 \%$ in rural areas, with both cases and controls dominantly living in urban areas. A statistically significant difference was observed for gender, with a dominance of male TB cases $(63.24 \%$ vs. $52.09 \%$ in the control group). TB cases were slightly younger (mean age of 45.17 years $\pm 15.74 \mathrm{SD}$, compared to controls with mean age of $47.28 \pm 14.12 \mathrm{SD}$ ) and lived in statistically significant bigger households, with an average 4.66 members than $\mathrm{HH}$ size of 4.36 in controls. For ethnicity, most TB cases were Albanian (50.65\%) or Macedonian (37.43\%), followed by Roma (7.54\%) and Turkish (4.38\%) and, given the study design, there was no statistically significant difference between the groups $\left(\chi^{2}=3.46, \mathrm{df}=5, P=0.63\right)$.

Analysis of socio-economic status through funds available to households as a proxy showed that households with TB patients were at the lower end of the scale, with a statistically significant lower sum of 18.78 Macedonian Denars $(\mathrm{MKD}) \pm 11.39 \mathrm{SD}$, compared to their controls with 30.25
Table 1. Demographic characteristics of study population - TB cases $(n=315)$ and controls $(n=290)$

\begin{tabular}{|c|c|c|c|}
\hline & TB cases & Controls & $\boldsymbol{P}$ \\
\hline Region & & & 0.92 \\
\hline Skopje & $47.58 \%$ & $47.59 \%$ & \\
\hline Polog & $14.96 \%$ & $14.90 \%$ & \\
\hline South-West & $8.45 \%$ & $8.38 \%$ & \\
\hline South-East & $7.42 \%$ & $7.46 \%$ & \\
\hline North-East & $7.24 \%$ & $7.21 \%$ & \\
\hline Pelagonija & $5.93 \%$ & $5.93 \%$ & \\
\hline East & $5.28 \%$ & $5.28 \%$ & \\
\hline Vardar & $3.14 \%$ & $3.25 \%$ & \\
\hline Place of residence & & & 0.41 \\
\hline Urban & $52.14 \%$ & $53.78 \%$ & \\
\hline Rural & $47.86 \%$ & $46.22 \%$ & \\
\hline Gender & & & $<0.01$ \\
\hline Female & $36.76 \%$ & $47.91 \%$ & \\
\hline Male & $63.24 \%$ & $52.09 \%$ & \\
\hline Mean age of respondents & $45.17 \%$ & $47.28 \%$ & 0.08 \\
\hline Mean HH size & $4.66 \%$ & $4.36 \%$ & 0.04 \\
\hline $\begin{array}{l}\text { Mean funds available per } \\
\text { HH member (MKD) }\end{array}$ & $4532.33 \%$ & $5707.00 \%$ & $<0.01$ \\
\hline Ethnicity & & & 0.63 \\
\hline Macedonian & $37.43 \%$ & $44.85 \%$ & \\
\hline Albanian & $50.65 \%$ & $43.84 \%$ & \\
\hline Roma & $7.54 \%$ & $6.25 \%$ & \\
\hline Turkish & $4.38 \%$ & $4.18 \%$ & \\
\hline Education & & & 0.03 \\
\hline No formal education & $2.65 \%$ & $3.12 \%$ & \\
\hline Unfinished primary school & $10.05 \%$ & $9.78 \%$ & \\
\hline Completed primary school & $41.74 \%$ & $30.73 \%$ & \\
\hline Completed high school & $39.55 \%$ & $43.45 \%$ & \\
\hline Completed university education & $4.54 \%$ & $9.36 \%$ & \\
\hline Employment status & & & $<0.01$ \\
\hline Public administration & $7.04 \%$ & $9.48 \%$ & \\
\hline Self-employed & $9.13 \%$ & $13.09 \%$ & \\
\hline Employer & $11.25 \%$ & $23.05 \%$ & \\
\hline Unemployed & $72.44 \%$ & $52.24 \%$ & \\
\hline NGO & $0.32 \%$ & $2.14 \%$ & \\
\hline
\end{tabular}

$\mathrm{TB}=$ Tuberculosis; $\mathrm{HH}=$ Households; $\mathrm{MKD}=$ Macedonian Denar

$\mathrm{MKD} \pm 10.26 \mathrm{SD}(\mathrm{t}=-5.22, \mathrm{df}=566, P<0.01)$. Given the bigger $\mathrm{HH}$ size in cases, the total funds available to $\mathrm{HH}$ were also reflected in the average funds available per member in $\mathrm{HH}$ with TB patients, which were significantly lower than in the control $\mathrm{HH}(\mathrm{t}=-3.22, \mathrm{df}=566, P<0.01)$.

Significant differences were noted in educational status, as a majority of TB cases were less educated than their controls, with a completed primary school education (41.74\%) or high school (39.55\%), compared to controls where these percentages were $30.73 \%$ and $43.45 \%$, respectively. This, in turn, was reflected in employment status, with a significantly higher $72.44 \%$ of $\mathrm{TB}$ patients who were unemployed, compared to $52.24 \%$ of their controls. $11.25 \%$ cases ran their own business, 9.13\% were self-employed and only $7.04 \%$ worked in public administration, compared to $23.05 \%$, 
$13.09 \%$, and $9.48 \%$ in the same categories of their controls $\left(\chi^{2}=25.65, \mathrm{df}=5, P<0.01\right)$.

Reasons for unemployment were diverse and statistically significant. The most frequent answer among TB cases was that they were actively seeking but could not find any job (26.24\%), were bankruptcy trustees following the privatization of enterprises $(20.32 \%)$, or they were caretakers of the family (19.67\%). 16.34\% were retired, $7.14 \%$ students and $6.38 \%$ felt too sick to work (Figure 1).

\section{Access to healthcare}

More than one third of respondents in the total sample $(37.04 \%)$ were in need of healthcare in the last 30 days and $44.72 \%$ were in need in the past 12 months. Of them, more than two thirds $(82.12 \%)$ had been to see a doctor for a personal problem or examination, $15.14 \%$ for a child, and the rest for another member of the family. During the last visit, $47.22 \%$ respondents had available only one doctor, one third (34.28\%) could choose between 2 doctors and $18.51 \%$ had a choice of more than three doctors. The main reasons for visits were routine control examination $(49.87 \%)$ or dental service $(25.05 \%)$.

Most TB cases (43.02\%) needed to see a doctor in the last 30 days and $47.75 \%$ in the past year, with corresponding

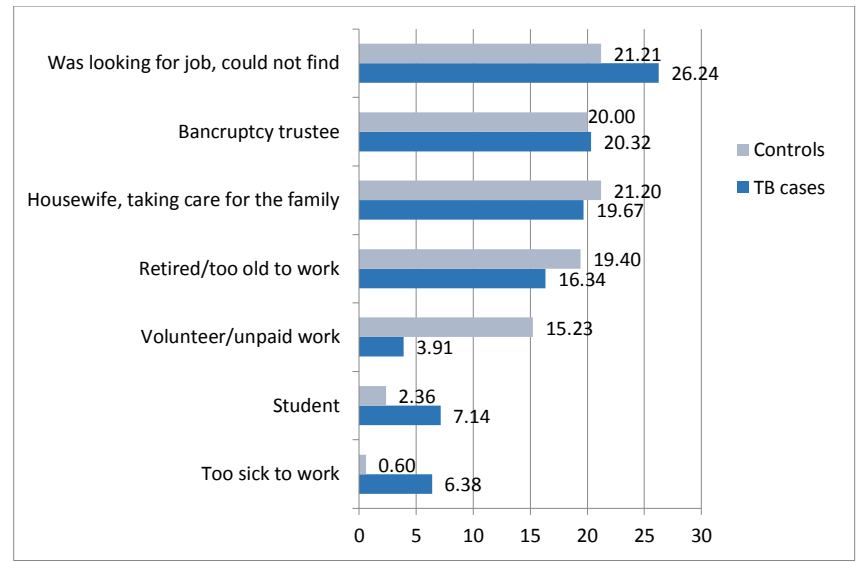

Figure 1. Distribution of answers for the question What is the main reason for your unemployment? in unemployed cases $(n=228)$ and controls $(n=151)$

Table 2. Distribution of responses on the question When was the last time you or your child had a need for healthcare? in cases $(n=302)$ and controls $(n=282)$

\begin{tabular}{lll}
\hline & TB cases (\%) & Controls (\%) \\
\hline In the last 30 days & $130(43.02)$ & $86(30.51)$ \\
\hline More than a month and less than a year & $144(47.75)$ & $117(41.48)$ \\
1-2 years ago & $4(1.26)$ & $19(6.68)$ \\
2-3 years ago & $2(0.69)$ & $10(3.52)$ \\
3-5 years ago & $0(0.00)$ & $11(3.94)$ \\
More than 5 years ago & $4(1.34)$ & $25(8.85)$ \\
Never & $18(5.94)$ & $14(5.02)$ \\
Total & $302(100)$ & $282(100)$ \\
\hline
\end{tabular}

$\chi^{2}=52.96, \mathrm{df}=6, P<0.01$
$30.51 \%$ and $41.48 \%$ in the control group. The proportion of respondents in the control group who sought healthcare was significantly higher in all other categories (Table 2).

In the total sample, for all respondents who needed healthcare in the past 30 days or in the past year, as high as $83.89 \%$ had received the needed services, but $16.15 \%$ did not receive the service for various reasons. Of these, more than half were TB patients (53.10\%), compared to $46.90 \%$ controls.

Reasons for not receiving service when in need in both cases and controls were diverse and reflected both financial and non-financial issues (Figure 2). Significant differences were observed between cases and controls in the answers $I$ could not afford to pay for service (19.40\% cases vs. $16.30 \%$ controls, $P=0.04)$, did not have money for transport $(15.50 \%$ cases vs. $19 \%$ controls, $P=0.04)$, did not know where to seek healthcare $(22.00 \%$ cases vs. $14.80 \%$ controls, $P=0.04)$, with no difference in the answer did not have transport $(22.40 \%$ vs. 14.30, $P=0.08)$. The highest proportion of controls (26.30\%) thought they were not that sick to seek healthcare compared to only $12.80 \% \mathrm{~TB}$ cases $(P=0.05)$ and rejection by health workers was reported only in TB cases, with $7.90 \%, P=0.02$. None of the respondents stated that the doctor does not have appropriate equipment or drugs or have treated them badly. When analyzed by region, the highest proportion of respondents who did not receive healthcare due to inability to pay for the service was in the Southwest (55.62\%), Southeast (22.25\%), and $11.09 \%$ in both Polog and Northeast region $\left(\chi^{2}=35.50, \mathrm{df}=7, P<0.01\right)$.

\section{Costs associated with healthcare}

Average expenditures associated with latest healthcare service are presented in Table 3. An analysis of costs associated with healthcare showed higher mean values for all categories in the control group, except costs for transport that were higher for the TB cases, but this difference was not statistically significant. Statistically significant differences among cases and controls were observed only in costs of drugs and tests. Average costs for cases ranged from 119.19 MKD for service to $362 \mathrm{MKD}$ for transportation costs, but with big standard deviations pointing to certain extremes with maximum sums of 1,000 MKD for tests to 9,500 MKD paid for transportation

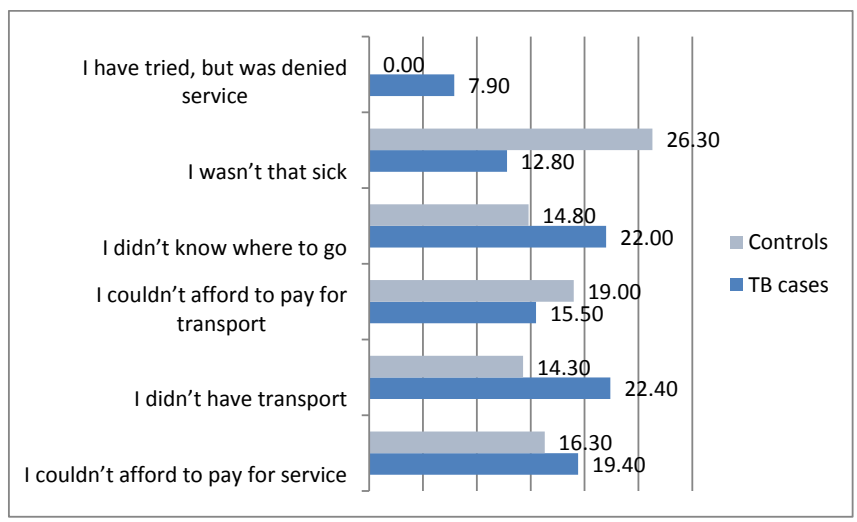

Figure 2. Distribution of answers for the question What was the main reason you did not receive healthcare in cases $(n=167)$ and controls $(n=136)$ 
to health facility.

Total costs incurred for healthcare in the past 4 weeks were higher in TB patients (2085.09 MKD $\pm 2310.66 \mathrm{SD})$, as well as total costs for hospitalization $(2311.13 \mathrm{MKD} \pm 8102.01$ $\mathrm{SD})$ compared to controls with total costs in the past 4 weeks of $1763.00 \pm 3024.08 \mathrm{SD}$ and 1257.48 MKD \pm 3054.25 for hospital care.

The multivariate logistic regression analysis of sociodemographic characteristics associated with access to healthcare showed that access was strongly associated with educational status, gender, ethnicity, and employment status, while age and region did not prove to have influence on access Table 4.

\section{Discussion}

Our survey described the main SDH for TB patients in RM in comparison with controls drawn from the general population that were disease free. The study confirmed the evidence of clustering of TB in certain regions and ethnic groups as documented in the regular recording and reporting system, but also added other determinants that are not routinely collected, such as lower educational status, ethnicity, and lower socio-economic status (as measured by available funds per family member in the study). TB patients were also more likely to be unemployed or unable to work because they feel too sick to work, although the unemployment rate was also high in controls; both groups were above the average reported by the State Statistical Office (24).

Although the distribution of health services has been identified as a specific strength of Macedonian healthcare system (25) our analysis of access to healthcare has shown that there are still groups in the population that do not receive healthcare for various reasons and have therefore only partially confirmed the main research hypothesis. In our study, TB patients were more likely to not receive care when in need, which is in contrast with the national policy for guaranteed free of charge treatment of TB patients in the framework of Preventive TB program funded by the state budget and implemented by Ministry of Health (26), complemented by activities funded by the Global Fund to Fight HIV/AIDS, TB, and Malaria (27). This is a finding that certainly points to the need for further exploration of the underlying reasons. However, the proportion of respondents that did not receive care is almost identical to the $86.00 \%$ of insured individuals reported by the HIF in 2012 (28), given that enrollment in a HIF scheme (based on social health insurance through compulsory payroll contributions amounting to $8.60 \%$ of gross earned wages) provides an entrance to health services and access to a wide range of services defined in the basic benefit package.

Average sums associated with payments for health services by TB patients were lower in TB patients compared to controls, which is in accordance with national policy that defines TB diagnostics and treatment as free of charge. Higher payments

Table 3. Distribution of costs associated with treatment in case $(n=315)$ and controls $(n=290)$

\begin{tabular}{|c|c|c|c|c|c|c|c|c|c|}
\hline & \multicolumn{4}{|c|}{ TB cases } & \multicolumn{4}{|c|}{ Controls } & \multirow{2}{*}{$P$} \\
\hline & Min & Max & Mean & SD & Min & Max & Mean & SD & \\
\hline Cost of service & 0 & 8000 & 119.19 & 677.47 & 0 & 3000 & 183.53 & 472.72 & 0.25 \\
\hline Cost of diagnostic tests & 0 & 1000 & 52.61 & 152.56 & 0 & 1700 & 164.38 & 301.54 & $<0.01^{*}$ \\
\hline Cost of transport & 0 & 9500 & 362.09 & 1057.59 & 0 & 15000 & 258.72 & 1577.65 & 0.51 \\
\hline
\end{tabular}

${ }^{*} P$-value represents the significance value of t-test for independent samples.

Table 4. Multivariate analysis for predictors of access to healthcare in TB patients $(n=315)$

\begin{tabular}{|c|c|c|c|c|}
\hline & \multirow{2}{*}{ OR } & \multicolumn{2}{|c|}{$95 \% \mathrm{Cl}$} & \multirow{2}{*}{$\boldsymbol{P}$} \\
\hline & & Lower & Upper & \\
\hline \multicolumn{5}{|l|}{ Age, years } \\
\hline $60+$ vs. $51-59$ vs. $41-49$ vs. $31-40$ vs. $21-30$ vs. $<20$ & 1.24 & 0.82 & 1.25 & 0.82 \\
\hline \multicolumn{5}{|l|}{ Region } \\
\hline Skopje vs. South-West vs. South-East vs. East vs. North-West vs. Polog vs. Pelagonija vs. Vardar & 1.02 & 0.91 & 1.10 & 0.96 \\
\hline \multicolumn{5}{|l|}{ Educational status } \\
\hline University vs. high school vs. primary school vs. unfinished primary school vs. no formal education & 3.22 & 2.49 & 4.16 & $<0.01$ \\
\hline \multicolumn{5}{|l|}{ Gender } \\
\hline Male vs. female & 5.42 & 3.63 & 8.10 & $<0.01$ \\
\hline \multicolumn{5}{|l|}{ Employment status } \\
\hline Unemployed vs. employed & 1.16 & 1.10 & 1.39 & 0.01 \\
\hline \multicolumn{5}{|l|}{ Ethnicity } \\
\hline Macedonian vs. Albanian vs. Roma vs. Turkish & 3.86 & 2.46 & 5.22 & $<0.01$ \\
\hline
\end{tabular}


for transport are likely to be associated with regional positioning of TB dispensaries where TB patients are referred for treatment and control examinations (29).

However, total costs were higher for both healthcare in the past 4 weeks and hospital care in the past year incurred by TB patients, with huge statistical deviations to the mean. This finding requires particular attention and further investigation, as it may indicate existence of co-morbidities not related to TB disease that require hospitalization and additional diagnostic procedures as well as the existence of catastrophic health expenditures, given the lower socio-economic status of most of the patients (30).

The proportion of TB patients in need of seeing a doctor in the last 30 days was higher, most likely associated with TB disease and the practice to dispense drugs to TB patients once a month, as per the national policy (30). Access to healthcare was strongly associated with the educational status of TB patients, which in absence of available literature for comparison with neighboring or similar countries, is comparable to a U.S. study showing that individuals who attended college are more likely to receive preventive care due to greater access to healthcare, but with limited evidence that marital status, health insurance, income, or wealth are primary mechanisms (31). Gender, employment status, and ethnicity were also associated with access to health services for both cases and controls.

Although our survey identified the existence of certain regional differences in availability and access to health services which are associated with both material (inability to pay for service, lack of transport) and non-material factors (lack of knowledge where to seek healthcare, denial to provide care, etc.), results from the multiple logistic regression did not reveal any such association.

\section{Study strengths and limitations}

Survey of this type has never been performed in RM, thus we can emphasize this fact as a strength of the study, providing baseline information on possible factors that influence access to healthcare of the population.

Limitations are those typical of self-reported data and the nested case-control study design, with probability of oversampling respondents with similar characteristics, associated with TB disease as the main selection criteria of cases that can somehow act as confounder of the findings. Results cannot provide evidence on causality and selection bias as well cannot be estimated.

\section{Conclusion}

This was the first part of a series of planned surveys, since a survey of this type has never been conducted in the country and the gap in health status among poor and wealthier populations has never been systematically studied, thus leading to policies and programs that are targeting the entire population, rather than targeting vulnerable groups.

The study documented the basic SDH of TB patients in $\mathrm{RM}$, as well as barriers in access to healthcare, and provides useful baseline information aimed to facilitate determination of future efforts. Barriers to access health services were significantly associated with gender, employment status, ethnicity and education; therefore, the main recommendation from this study is to address these aspects and the promotion of approaches and strategies as well as tailoring TB campaigns and educational efforts that will tackle the underlying roots of inequity in access. Monitoring of SDH should be integrated into the routine recording and reporting system.

In terms of financial protection, it is necessary to ensure that healthcare services for $\mathrm{TB}$ patients are provided in compliance with the national strategy in a way that minimises direct and indirect costs, in addition to other social protection interventions, such as family-focused social work support and essential social transfers, in cash and in kind, to assure at least regular control examinations and proper nutrition.

Authors plan to further study the SDH of TB patients that will effectively contribute towards better TB control in RM.

\section{Acknowledgments}

The study was conducted by Institute of Public Health, as secondary recipient of grant funds from Ministry of Health, as Primary Recipient of Grant No. MKD-011-G-04-T funded by Global Fund to Fight HIV/AIDS, TB and Malaria, under Operational Research objective. The funding sources had no involvement in study design, nor in the collection, analysis and interpretation of the data, nor in writing the article and the decision to submit it for publication.

Ethical issues

The study was granted ethical approval by Doctors Chamber in March, 2013.

Competing interests

DGN is Coordinator of GFATM funded project on TB implemented by Ministry of Health. FT declares no conflict of interest.

Authors' contributions

DGN and FT were responsible for study design, survey logistics, recruitment of interviewers, supervision of all research phases and preparation of final report. The authors alone are responsible for the content of this report.

Authors' affiliations

${ }^{1}$ Department of Social Medicine, Faculty of Medicine, University Ss. Cyril and Methodius, Skopje, Macedonia. ${ }^{2}$ National Institute of Public Health, Department of Social Medicine, Faculty of Medicine, University Ss. Cyril and Methodius, Skopje, Macedonia.

\section{References}

1. de Looper M, Lafortune G. Measuring disparities in health status and in access and use of health care in OECD countries OECD Health Working Papers No. 43 [Internet]. 2009. Available from: http://www.oecd-ilibrary.org/docserver/download/5ksm88c0r7kj. pdf?expires $=1411378248 \&$ id $=i d \&$ accname $=$ guest $\&$ checksum $=2$ 360B0C612F7E117249DC207531687E0

2. Mackenbach JP, Stirbu I, Roskam AJ, Schaap M, Menvielle G, Leinsalu $M$, et al. Socio-economic inequalities in mortality and morbidity: a cross-European perspective. In: Tackling Health Inequalities in Europe: an Integrated Approach. Eurothine Final Report. Rotterdam: Department of Public Health, University Medical Centre Rotterdam; 2007.

3. Mackenbach JP, Meerding WJ, Kunst AE. Economic Costs of Health Inequalities in the European Union. $J$ Epidemiol Community Health 2011; 65: 412-9. doi: 10.1136/ jech.2010.112680 
4. Blas E, Sivasankara Kurup A. Equity, social determinants and public health programmes. Geneva: WHO; 2010

5. Constitution of the World Health Organization [internet]. WHO, Basic Documents, Forty-fifth edition, Supplement, October 2006. Available from: http://www.who.int/governance/eb/who_ constitution_en.pdf

6. [No authors listed]. What is health? The ability to adapt. Lancet 2009; 373: 781. doi: 10.1016/s0140-6736(09)60456-6

7. Huber M, Knottnerus JA, Green L, van der Horst H, Jadad AR, Kromhout D, et al. How should we define health? BMJ 2011; 343: d4163. doi: 10.1136/bmj.d4163

8. Jadad AR, O'Grady L. How should health be defined BMJ 2008; 337: a2900. doi: 10.1136/bmj.a2900

9. Larson JS. The conceptualization of health. Med Care Res Rev 1999; 56; 123-36.

10. World Health Organization (WHO). Closing the Gap in a Generation: Health Equity through Action on the Social Determinants of Health: Commission on Social Determinants of Health Final Report. Geneva: World Health Organization, Commission on Social Determinants of Health; 2008.

11. Health Nexus and Ontario Chronic Disease Prevention Alliance. Primer to Action: Social Determinants of Health [internet]. 2008. Available from: http://en.healthnexus.ca/sites/en.healthnexus. ca/files/resources/primer_to_action.pdf

12. Exworthy M. Policy to tackle the social determinants of health: using conceptual models to understand the policy process. Health Policy Plan 2008; 23: 318-27. doi: 10.1093/heapol/czn022

13. World Health Organization (WHO). Global strategy and targets for tuberculosis prevention, care and control after 2015 [internet]. 2013. Available from: http://www.who.int/tb/post_2015_tb_ presentation.pdf

14. WHO, Stop TB Partnership, The Global Fund to Fight AIDS, TB and Malaria. Reach the 3 million: Find. Treat. Cure TB. Geneva: WHO; 2014

15. World Health Organization (WHO). Health systems in transition. The former Yugoslav Republic of Macedonia: WHO; 2002.

16. Macedonia - Constitution [internet]. Available from: http://www. servat.unibe.ch/icl/mk00000_html
17. Lazarevik V, Donev D, Gudeva Nikovska D, Kasapinov B. Three periods of health system reforms in Republic of Macedonia (1991-2011). Prilozi 2012; 33: 175-89.

18. World Health Organization (WHO). Global tuberculosis report. Geneva: WHO; 2013

19. State Statistical Office, 2013. Available from: http://www.stat.gov. mk/OblastOpsto_en.aspx?id=2

20. WHO Health statistics and information systems. World Health Survey Instrument and related documents [internet]. Available from: http://www.who.int/healthinfo/survey/instruments/en/

21. Glewwe P. Household Sample Surveys in Developing and Transition Countries, 2010.

22. McCrum-Gardner E. Which is the correct statistical test to use? Br J Oral Maxillofac Surg 2008; 46: 38-41. doi: 10.1016/j. bjoms.2007.09.002

23. Lang T. Documenting research in scientific articles: guidelines for authors: 2. Reporting hypothesis tests. Chest 2007; 131: 62832. doi: $10.1378 /$ chest.06-2088

24. 20 years of independent Macedonia [internet]. State Statistical Office, 2012. Available from: http://www.stat.gov.mk/Publikacii/2 OYearsOfINDEPENDENTMACEDONIA.pdf

25. World Health Organization (WHO). Health systems in transition. The former Yugoslav Republic of Macedonia: WHO; 2006.

26. Preventive tuberculosis program in Republic of Macedonia. Ministry of Health, 2014.

27. Ensuring high quality and sustainable DOTS interventions in Republic of Macedonia. Global Fund to Fight HIVIAIDS, Tuberculosis and Malaria, 2014.

28. Insured individuals in Republic of Macedonia/Health Insurance fund, 2012.

29. National TB Strategy 2008-2012. Ministry of Health, 2012.

30. Tanimura $T$, Jaramillo $E$, Weil $D$, Raviglione $M$, Lonnroth $K$. Financial burden for tuberculosis patients in low- and middleincome countries: a systematic review. Eur Respir J 2014; 43: 1763-75. doi: 10.1183/09031936.00193413

31. Fletcher JM, Frisvold DE. Higher Education and Health Investments: Does More Schooling Affect Preventive Health Care Use? J Hum Cap 2009; 3: 144-76. doi: 10.1086/645090 